\title{
The variation of floods in the middle reaches of the Yangtze River and its teleconnection with El Niño events
}

\author{
Y.-J. Wu ${ }^{1}$, W. A. Gough ${ }^{2}$, T. Jiang ${ }^{3}$, and H.-T. Kung ${ }^{4}$ \\ ${ }^{1}$ School of Urban And Environmental Sciences, Central China Normal University, Wuhan 430079, China \\ ${ }^{2}$ Environmental Science, University of Toronto at Scarborough, 1265 Militaty Trail, Scarborough, Ontario, M1C 1A4, Canada \\ ${ }^{3}$ Nanjing Institute of Geography and Limnology, CAS, Nanjing 210008, China \\ ${ }^{4}$ Department of Earth Sciences, The University of Memphis, Memphis, Tennessee 38152, USA
}

Received: 7 July 2005 - Revised: 26 January 2006 - Accepted: 26 January 2006 - Published: 6 February 2006

\begin{abstract}
Middle reaches of the Yangtze River are the worst flooded segments along the Yangtze River. It is important to understand and study the variations of frequency and magnitude of historical floods in this area and how were they related to or affected by EI Niño in a long historical period. We applied the statistics and time series to study and analyze historical floods (1470-2000) and EI Niño events (1525-1995). The results show that the more floods occurred in the latest 200 years. The power-spectral analysis suggests the main cycle of flood variation is longer than that of EI Niño events. El Nino shows the fluctuations of about 2-year and 3 4 year period while the flood variation is not so significant but can also be identified in the period of 2, 8 and 40 years (it exceeds the level of confidence 0.03). Time series analyses of the fluctuation of flood and El Nino indicate that there is a significant correlation between the two at both high and moderate frequency sections. The result shows that the response of the floods along the middle reaches of the Yangtze River to the effects of El Nino events is not only delayed one or more than one year as suggested by many Chinese scientists, but it also can be somewhat longer delayed up to about 8 years. The result also indicates that the shorter the interval of EI Niño events, the sooner the flood events follows. In other words, flood could be delayed with longer time if the interval time of EI Niño events is longer.
\end{abstract}

\section{Introduction}

As the third largest river in the world and the largest one in China, the Yangtze River is very important to human society in China. It reflects the Chinese history and prosperity and development of Southern China. Since ancient times, people in the Yangtze Rive basin have suffered from and fighting

Correspondence to: $\mathrm{Y}$. Wu

(wuyijin@public.wh.hb.cn) against flood disasters from generation to generation. It has long been known as "China's sorrow" for the lives that have lost and properties have been damaged by the frequent and violent floods.

Originating in Tibetan Plateau, the river flows eastward through central China on its way to Donghai (East China Sea) in Shanghai on China's east coast (Fig. 1). In its middle section, it passes through the immense Jianghan Plains from Yichang to Wuhan, named Jing-Jiang. Because of the limited capacity of flood discharge, this region is the worst flooding area of the whole Yangtze River. For instance, the capacity of flood discharge in Jing-Jiang is about $60000 \mathrm{~m}^{3} / \mathrm{s}$. However, there were an estimated 108 disastrous breaks in the river embankments across the Jing-Jiang reaches from $1525 \mathrm{AD}$ to $1995 \mathrm{AD}$ and more than 24 years in which flood discharges have exceeded this capacity after 1892 (Table 1), causing great damage.

The extreme flood discharges were caused by heavy rainfall in the upper reaches of the Yangtze River valley. It is commonly known that the climate of China is strongly influenced by the East Asian monsoon. The primary physical manifestation of the summer monsoon is persistent, heavy precipitation identified as a coherent and well-defined rainband. Because of the variations in monsoons, the rainband has inter-annual variability anomalies over the Yangtze River valley that causes yearly rainfall totals to fluctuate greatly, especially rainfall during the flooding season.

El Niño is a recurring pattern of climate variability in the eastern equatorial Pacific that is characterized by anomalies with warming periods of sea-surface temperature. As the remarkable connective signal between the entire near-globalscale climatic change and sea-surface temperature, EI Niño events profoundly affect the regional climate. There have been thus far many studies on EI Niño and its relation to global and regional climates through atmospheric circulation (Chang et al., 2001). And also recent research shows that EI 


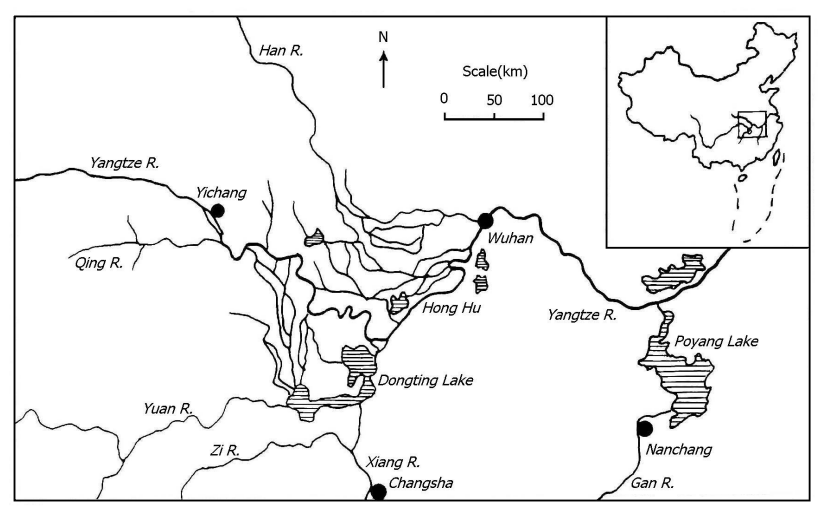

Fig. 1. The middle reaches of the Yangtze River basin.

Niño Events has some effect on regional long-term precipitation in China.

\section{Data resource and process}

Quinn and Neal (1992) has presented the data about the strength of EI Niño events. They identified, evaluated, and examined many detailed reports from sailing vessel logs, diaries of conquistadors and their entourages, missionaries, pirates, privateers, historians, geographers, engineers, geologists, hydrologists, newspapers, and scientists. They provided a rather broad and extensive information on areas directly affected by EI Niño and areas affected by other unusual conditions related to EI Niño (e.g. the droughts that often affect southeastern Peru and adjacent parts of Bolivia during an EI Niño) in the period of 1525 to 1987. Historical EI Niño Events Data and the strength of EI Niño events are classified into several categories, that is, very strong (VS), strong (S), and moderate $(\mathrm{M})$. Among them, the $\mathrm{S}+, \mathrm{M}+$ and $\mathrm{M}-$ are added to supplement those EI Niño events whose intensities are not in the standard categories. For the compound type of activity over the distant past, the signals of $\mathrm{M} / \mathrm{S}$ or $\mathrm{M}-/ \mathrm{M}+$ are used to cover two events of different intensities.

For quantitative purposes, those categories are tabulated in as shown in Table 2.

Trenberth (1997) defined the EI Niño Event as 5-month running averages of sea surface temperature (SST) anomalies in the El Niño 3.4 region $\left(5^{\circ} \mathrm{N}-5^{\circ} \mathrm{S}, 120^{\circ}-170^{\circ} \mathrm{W}\right)$ exceeding $0.4^{\circ} \mathrm{C}$ for 6 months or more. We find this definition matches very well with W.H.Quinn's for their common years during modern time. Therefore, the EI Niño events time series defined by W.H.Quinn is extended to 1995 by adding the EI Niño events 1991 1992, 1993 and 1994 1995 derived from Kevin E. Trenberth's results.

As is probably well know, the Chinese have the best and most complete phonological records that exist (Rosenberg, 1982). During the Ming and Ch'ing dynasties from the 15th through the 18th centuries, Chinese regional geographical records (gazette) were carefully reviewed so that archives of historical floods, droughts, and many other climatic events are now available for this study. In this paper, historical flood data are derived from "flood and drought distribution atlas of China in the last 500 years" (China Central Meteorology Bureau, 1989). Data have been compiled and sorted for the selected stations in the middle reaches of Yangtze Rive such as Yichang, Jingzhou, Yueyang, and Wuhan. These data are relative complete and continuous. The location of these stations are well distributed and they are in the proximity to flood-sever areas. The data are extended to modern time by methods used in above atlas and converted into rainfall by the method proposed by Anyuan et al. (1999). Therefore, both frequency and magnitude of floods and total amount of rainfall are calculated to check the data consistency.

The flood data used in this paper are from 1470 to 2000 and spatially weighted using Thiessen polygons method (Linsley et al., 1975) to create a "middle reaches of Yangtze River basin" flood index for each year.

\section{Calculation and analysis}

In this paper, we attempt to study the variation and fluctuating of both floods in the middle reaches of the Yangtze River and EI Niño events, and the relationships between the two based on some historical data by using statistic methods and time series analysis.

\subsection{The variation/cycle of historical floods}

By using the following model, the flooding indexes of the middle reaches of the Yangtse River are calculated to analyze the variation of floods.

$I_{f}=\frac{\sum_{i=1}^{4}\left(n_{1 i}+n_{2 i}\right)+3}{\sum_{i=1}^{4} N_{i}+10}$

Where $I_{f}$ is the flooding index of each 10-year period. $n_{1 i}$ and $n_{2 i}$ are the number of flood (degree 1) and extreme flood (degree 2) years respectively for the interval of 10 years. For the historical period, the degree of flooding is dependent on the damage described in historical documents (China Central Meteorology Bureau, 1989). $N_{i}$ is the total number of recorded years for the interval of 10 years. Since the historical yearly records are not always in succession, the value of $N_{i}$ is sometimes not exactly equal to 10 . $i$ represents the calculated station. The results are shown in Table 3.

It can be seen from Table 3 that most of more flood periods appears in the last 200 years. In order to understand this more easily, Fig. 2 is presented below based on the values from Table 3.

It is clear in Fig. 2 that with time both lower and higher points of index line show a steady rise. This is also reflected in the floating average line. It shows that there are two waves during the 330 years of 1470 1800. The amplitude of the two waves is not very large, which indicates less flooding events with milder variation during this period. However, the 
Table 1. Extreme Flood Discharges At Yichang Station After 1892 (discharge: $\mathrm{m}^{3} / \mathrm{s}$ ).

\begin{tabular}{cccccccc}
\hline Year & Discharge & Year & Discharge & Year & Discharge & Year & Discharge \\
\hline 1892 & 64600 & 1917 & 61000 & 1931 & 64600 & 1954 & 66800 \\
1896 & 71100 & 1919 & 61700 & 1936 & 62300 & 1958 & 60200 \\
1898 & 60600 & 1920 & 61500 & 1937 & 61900 & 1974 & 61600 \\
1905 & 64400 & 1921 & 64800 & 1938 & 61200 & 1981 & 70800 \\
1908 & 61800 & 1922 & 63000 & 1945 & 67500 & 1989 & 61800 \\
1909 & 61100 & 1926 & 60800 & 1946 & 62100 & 1998 & 63600 \\
\hline
\end{tabular}

Table 2. Intensity categories of historical EI Niño events and corresponding numeric value.

\begin{tabular}{ccccccccc}
\hline categories & very strong(VS) & $\mathrm{S}+$ & strong $(\mathrm{S})$ & $\mathrm{M}+$ & moderate $(\mathrm{M})$ & $\mathrm{M}-$ & $\mathrm{M} / \mathrm{S}$ & $\mathrm{M}-/ \mathrm{M}+$ \\
\hline digital & 3 & 2.5 & 2 & 1.5 & 1 & 0.5 & 0.5 & 0.3 \\
\hline
\end{tabular}

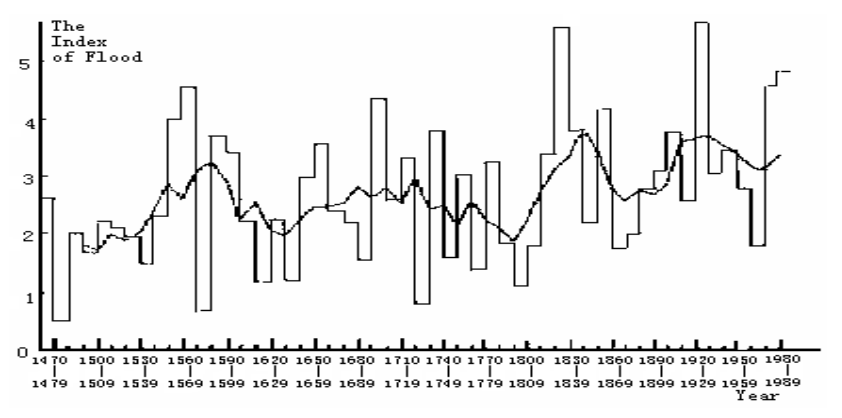

Fig. 2. The variation of flooding index $\left(I_{f}\right)$ since 1470 s (* floating average line).

floating average line has risen sharply since 1800. Within the 200 years since, there are more than two waves and the amplitude of them is larger than those before 1800, which shows that not only are floods more concentrated than before but also the interval time between floods is shorter. It also displays we are currently at the beginning of the third wave, which indicates that there will be more flooding disasters in the near future.

To analyze the cycles of historical floods, power-spectral analysis was applied to each of the members of floods series. The maximum lag $(k)$ in the analysis was set at 80 years. The computational procedure is the same as outlined in WMO's Technical Note on climate change (1966).

The result of smoothed power-spectral for floods (Fig. 3) shows the highest peaks of power-spectral occurs at $k=65,19$ and 4, exceeding 0.02, 0.03 and 0.01 degree of confidence respectively. That turns out the time series of the Yangtze floods have the cycles of about 2-year, and 8, and 40 years.

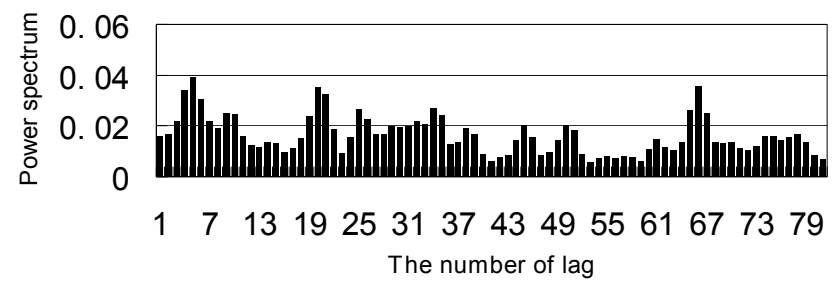

Fig. 3. The result of power spectrum for floods.

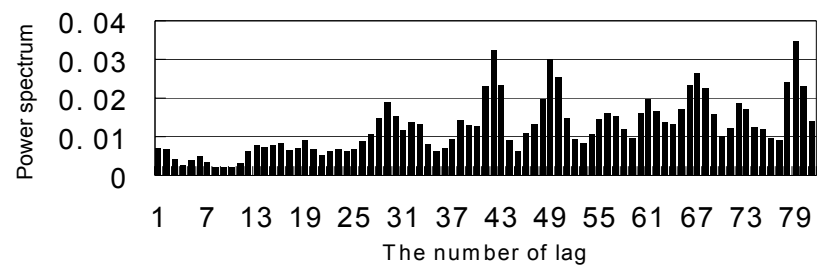

Fig. 4. The result of power spectrum for EI Niño events.

3.2 Cycles of EI Niño events and its teleconnection with the Yangtze floods

Same as the analysis of historical floods, The power-spectral for EI Niño events was also calculated and shown in Fig. 4, which reveals that the highest peaks of power-spectral occurs at $k=78,48$ and 41 , all of which exceed 0.01 degree of confidence. This simply means that the time series of EI Niño events have the cycles of about 2-year, and 3 4 years. This result is a little more convergent than that of Amy Clement and colleagues of the Lamont-Doherty Earth Observatory in Palisades, New York (2001). They say that ENSO occurs roughly every two to seven years as a result of heat and energy exchanging between the atmosphere and the oceans.

The cross-spectral was calculated to analyze the relationship between the power-spectrums of EI Niño events and the 
Table 3. Index of Yangtse River's flood since 1470s.

\begin{tabular}{cccccccccc}
\hline Year & Index & Year & Index & Year & Index & Year & Index & Year & Index \\
\hline $1470 \mathrm{~s}$ & 0.263 & $1580 \mathrm{~s}$ & $\bullet 0.067$ & $1690 \mathrm{~s}$ & $\bullet 0.156$ & $1800 \mathrm{~s}$ & $\bullet 0.111$ & $1910 \mathrm{~s}$ & $\boldsymbol{\Delta} 0.378$ \\
$1480 \mathrm{~s}$ & 0.053 & $1590 \mathrm{~s}$ & $\boldsymbol{\Delta} 0.371$ & $1700 \mathrm{~s}$ & $\boldsymbol{\Delta} 0.435$ & $1810 \mathrm{~s}$ & 0.180 & $1920 \mathrm{~s}$ & 0.258 \\
$1490 \mathrm{~s}$ & 0.200 & $1600 \mathrm{~s}$ & 0.342 & $1710 \mathrm{~s}$ & 0.261 & $1820 \mathrm{~s}$ & 0.340 & $1930 \mathrm{~s}$ & $\boldsymbol{\Delta} 0.583$ \\
$1500 \mathrm{~s}$ & 0.167 & $1610 \mathrm{~s}$ & 0.222 & $1720 \mathrm{~s}$ & 0.333 & $1830 \mathrm{~s}$ & $\boldsymbol{\Delta} 0.560$ & $1940 \mathrm{~s}$ & 0.308 \\
$1510 \mathrm{~s}$ & 0.222 & $1620 \mathrm{~s}$ & $\bullet 0.116$ & $1730 \mathrm{~s}$ & $\bullet 0.080$ & $1840 \mathrm{~s}$ & $\boldsymbol{\Delta} 0.380$ & $1950 \mathrm{~s}$ & 0.347 \\
$1520 \mathrm{~s}$ & 0.211 & $1630 \mathrm{~s}$ & 0.227 & $1740 \mathrm{~s}$ & $\boldsymbol{\Delta} 0.380$ & $1850 \mathrm{~s}$ & 0.220 & $1960 \mathrm{~s}$ & 0.280 \\
$1530 \mathrm{~s}$ & 0.196 & $1640 \mathrm{~s}$ & $\bullet 0.120$ & $1750 \mathrm{~s}$ & $\bullet 0.160$ & $1860 \mathrm{~s}$ & $\boldsymbol{\Delta} 0.420$ & $1970 \mathrm{~s}$ & 0.180 \\
$1540 \mathrm{~s}$ & $\bullet 0.149$ & $1650 \mathrm{~s}$ & 0.298 & $1760 \mathrm{~s}$ & 0.304 & $1870 \mathrm{~s}$ & 0.178 & $1980 \mathrm{~s}$ & $\boldsymbol{\Delta} 0.460$ \\
$1550 \mathrm{~s}$ & 0.231 & $1660 \mathrm{~s}$ & 0.357 & $1770 \mathrm{~s}$ & $\bullet 0.140$ & $1880 \mathrm{~s}$ & 0.200 & $1990 \mathrm{~s}$ & $\boldsymbol{\Delta} 0.500$ \\
$1560 \mathrm{~s}$ & $\boldsymbol{\Delta} 0.400$ & $1670 \mathrm{~s}$ & 0.240 & $1780 \mathrm{~s}$ & 0.326 & $1890 \mathrm{~s}$ & 0.279 & & \\
$1570 \mathrm{~s}$ & $\boldsymbol{\Delta} 0.455$ & $1680 \mathrm{~s}$ & 0.220 & $1790 \mathrm{~s}$ & 0.184 & $1900 \mathrm{~s}$ & 0.311 & & \\
\hline
\end{tabular}

The symbol "॥" stands for the period of more floods, while "•" stands for the period of less floods.

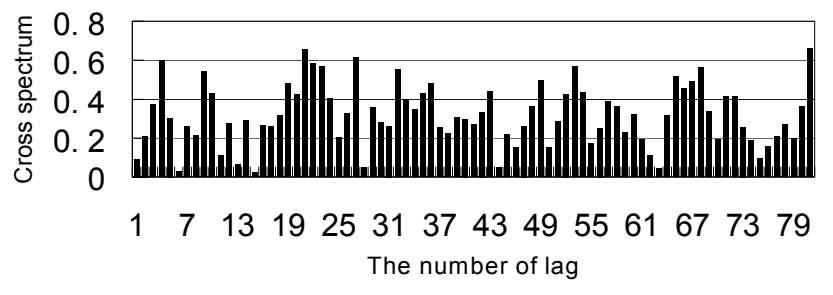

Fig. 5. The calculated result of coagulation function.

Table 4. Coincidence coagulation function peaks with different periods.

\begin{tabular}{lccc}
\hline Harmonic Value $(k)$ & 20 & 26 & 80 \\
Period (year) & 8 & 6 & 2 \\
\hline
\end{tabular}

Yangtze floods. The results (see Fig. 5) shows that there are three frequencies at which the significant correlation of those two time series excess 0.01 level at the peaks of $k=20$, 26 and 80 respectively. From that, it can be concluded that the responding of the floods in the middle reaches of the Yangtze River to EI Niño events happens not only at high frequency, but also at moderate frequencies (see Table 4). In other words, the floods in the middle reaches of the Yangtze River might occur not only in the following year of EI Niño events, but also as long as 8 years delay. The result also indicates that the shorter the interval between EI Niño events occurred, the sooner the following flood would happen. On the other side, delay time of flood will be longer when the interval of EI Niño events is extended.

\section{Conclusions and discussion}

At the moment, flood risk appears to be on the rise again, witnessing the series of floods of the last 20 years and the serious flood in 1998. Since it is now recognized that flood control does not meet its requirements, strengthening of flood control is underway. The most highlight event is the project of three gorges that will be taken its role in 2009. However, climate change will be still regarded in flood control. The variation and cycles of historical floods analyzed since 1470 in this paper show the floods may be frequent events, especially in the near future.

The cross-spectral analysis for the cycle of the Yangtze floods and El Nino events indicate that there is a significant correlation between the two at both high and moderate frequency sections. The result shows that the response of the floods along the middle reaches of the Yangtze River to the effects of El Nino events is not only delayed one or more than one year as suggested by many Chinese scientists, but it also can be somewhat longer delayed up to about 8 years. The result also indicates that the shorter the interval of EI Niño events, the sooner the flood events follows. In other words, flood could be delayed with longer time if the interval time of EI Niño events is longer.

Just as Ga et al. (1994) demonstrated that significant local effects of El Nino events in the Pacific Ocean can be extremely long-lived, not only lasting up to two years as other scientists think. The above result turns out that the oceanic effects of El Nino events on the floods along the middle reaches of the Yangtze River is not only immediately delay for one year or more as suggested by many Chinese scientists ${ }^{1}$, but also it can be somewhat further delayed up to 8 years or even longer.

Acknowledgements. The authors wish to thank L. King for his financial support working on this project. It would be impossible to finish this paper without his encouragement. We also want to extend our thanks to our colleagues in the Department of Geography, Justus-Liebig-University, Giessen, Germany for their kind help.

Edited by: P. Fabian and J. L. Santos

Reviewed by: J. Bendix and another anonymous referee

\footnotetext{
${ }^{1}$ http://www.coi.gov.cn/hyzh/ernn/ernn10.htm
} 


\section{References}

Chang, C.-P. and Chen, T.-J. G.: Tropical circulations associated with southwest monsoon onset and westerly surges over the South China Sea, Mon. Wea. Rev., 123, 3254-3267, 1995.

China Central Meteorology Bureau: The flood and drought distribution atlas of China in the latest 500 years, Meteorology Press, Beijing, in Chinese, 1989.

Clement, A. C., Cane, M. A., and Seager, R.: An orbitally driven tropical source for abrupt climate change, J. Climate, 14, 23692375, 2001.

Chang, C.-P., Harr, P., and Ju, J.: Possible Roles of Atlantic Circulations on the Weakening Indian Monsoon Rainfall - ENSO Relationship, J. Climate, 14, 2376-2380, 2001.

Ga, J. and He, H.: Decade-Scale Trans-Pacific Propagation And Warming Effects Of An El-Nino Anomaly, Nature, 370(6488), 360-363, 1994.
Linsley, R. K., Kohler, M. A., and Paulhus, J. L. H.: Hydrology for Engineers, 2nd edn, McGraw-Hill, Inc., New York, 1975.

Rosenberg, N. J.: Agricultural Meteorology in China, Bull. Amer. Mete. Soc., 63(3), 250-257, 1982.

Trenberth, K. E.: The definition of El Niño, Bull. Amer. Mete. Soc., 78(12), 2771-2777, 1997.

Quinn, W. H. and Neal, V. T.: The historical record of EI Niño events, in: Climate Since A.D. 1500, edited by: Bradley, R. S. and Jones, P. D., Routledge, 623-648, 1992

WMO: Climatic Change, Tech. Note, No. 79, 79 pp, 1966.

Anyuan, X., Yijin, W., and Shuming, C.: Reconstruction of rainfall in rainy season based on historical drought/floods grades, Adv. Atmos. Sci., 16(1), 147-153, 1999. 